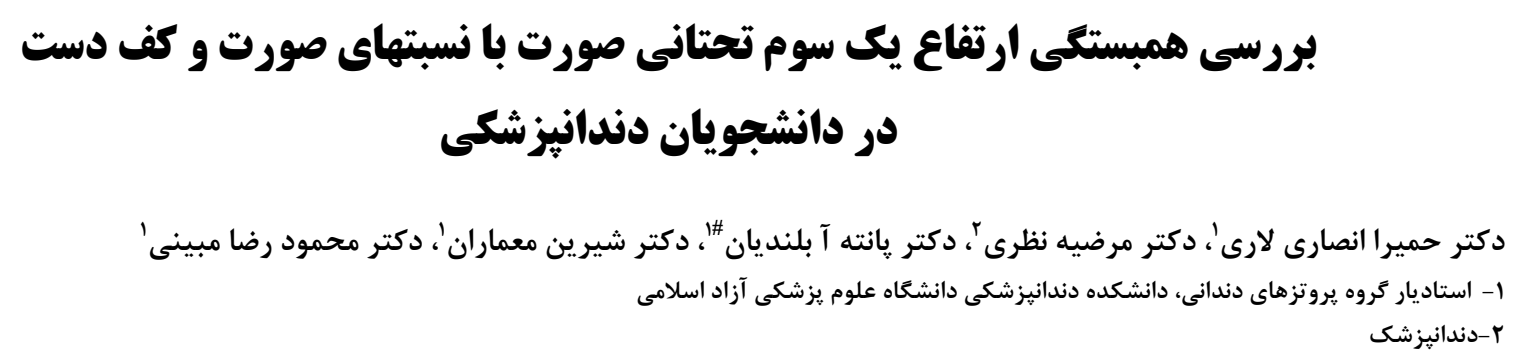

وصول مقاله:T/T/T

\title{
Assessment of the correlation between the height of the lower third of the face with facial proportions and antropometric measurement in dental students
}

\author{
Homeira Ansari lari ${ }^{1}$, Marzieh Nazari ${ }^{2}$, Pantea Bolandian ${ }^{1 \#}$,Shirin Memaran ${ }^{1}$, Mahmood reza Mobayeni $^{1}$ \\ ${ }^{1}$ Assistant professor, Prosthodontics Dept, Faculty of Dentistry, Tehran Medical Sciences, Islamic Azad University, Tehran, Iran \\ ${ }^{2}$ Dentist
}

\section{Abstract:}

Received:23 April 2019 ; Accepted : 17 June 2019

Background and aim: Assessment of vertical dimension of occlusion is an important step in the prosthodontic treatment of edentulous patients. The Objective of this study was to determine the correlation of the lower third of the face in occlusion and facial and palm indexes in dental students of Islamic Azad University of Tehran at 2017-2018.

Material and methods: In this correlation cross-sectional trial, 100 subjects (50 men \&50 women( were studied. The inclusion criteria were the subject's desire to participate in the study, facial symmetry, no history of trauma in the face and palm, and no history of facial plastic surgery.Facial indices and the palm size was recorded with a bolly gauge caliper with a precision of $0.1 \mathrm{~mm}$. the correlation between the height of the lower third of the face and each of the facial and palm indices was determined by Pearson correlation coefficient. Correlation coefficient (R) and consistency (R2) were calculated.

Results: The mean age of male was 23.02 years and the mean age of women was 24.6 years. All indices had a moderate correlation $(0.4<\mathrm{r}<0.6)$, except the "the distance between the hair line and between the two eyebrows" index which showed no correlation $(\mathrm{r}<0.2)$. The highest correlation ratio was found between "the distance between the sub-nasal and below the chin" and "the distance between the pupil of the eyes" and the least correlation ratio was also reported between "the distance between the sub-nasal and below the chin" and "the distance between the hair line and the two eyebrows".

Conclusions: It seems that anthropometric and palm indices can be used as auxiliary indices, and can not use lonely.

Key words: Anthropology, Vertical Dimension, Face

*Corresponding Author: drpbolandian@yahoo.com

J Res Dent Sci. 2019; 16 (3) :210-216. 
خلاصه:

سابقه و هدف: تعيين ارتفاع عمودى اكلوزن(VDO) مرحلهاى مهم از درمان يروتز براى بيماران بىدندان مىباشد. تحقيق حاضر با

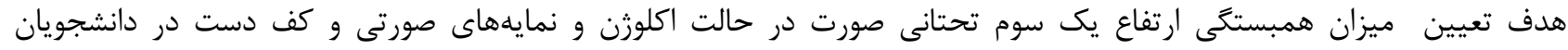

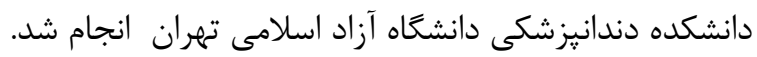

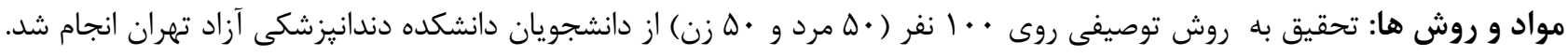

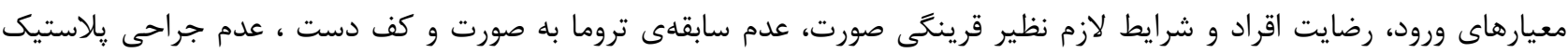

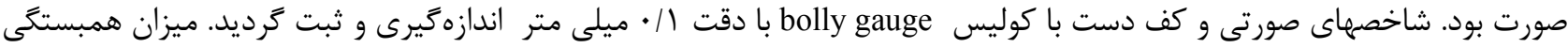

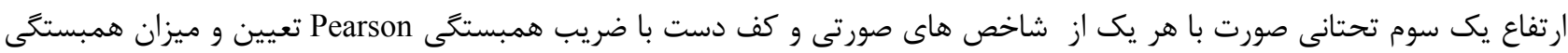

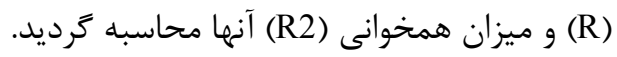

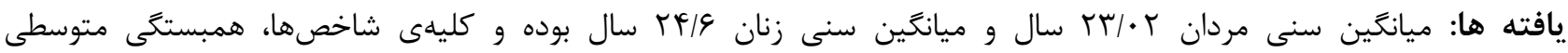

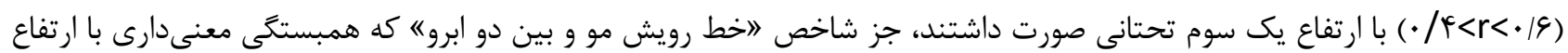

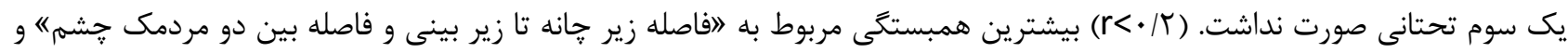

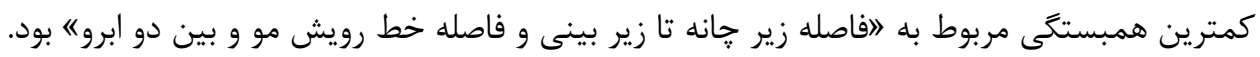

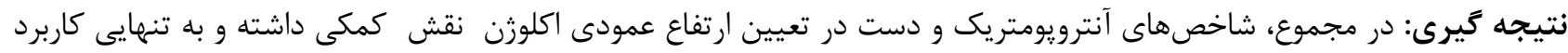

شد. ") و به وسيله Levin كسترش ييدا كرد Levin .اعلام كرد

مقدمه: كه از اين نسبت طلايى مىتوان براى دستيابى به لبخند زيبا در بررسى رابطهى صحيح عمودى فكين در حالت اكلوزن دندانيزشكى و متناسب با شكل صورت افراد بهره جست. (vertical dimension of occlusion ) طرف ديكر، درباره كاربردى بودن و همبستگى نسبتهاى مختلف صورت و حتى قد افراد، برخى تحقيقات انجام شده ولى نى

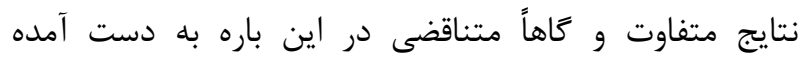

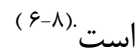

با توجه به اهميت VDO و مطالعات محدودى كه در جامعلى ايرانى دربارهى همبستگى نسبتهاى صورت با VDO انجام شده است، تحقيق حاضر با هدف تعيين اندازهاى

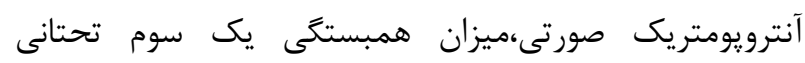

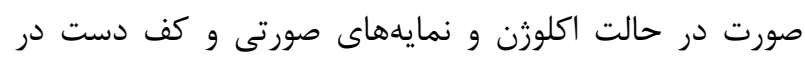
دانشجويان واحد دندانيزشكى دانشكاه آزاد اسلامى تهران در سال هاى له9 و و9 انجام شد.

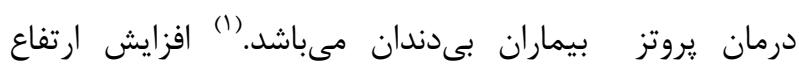
عمودى باعث مشكلات متعددى از جمله درد ماهيجههاى مضغى، مشكلات مفصل كيجكاهى-فكى، برخورد دندانها در هنغام صحبت، حالت مصنوعى صورت،تروما به مخاط و استخوان و تحليل استخوان، حالت تهوع و نيز عدم تحمل يروتز

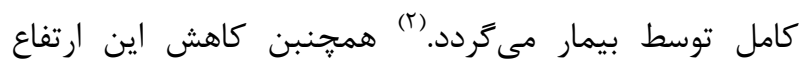
سبب كاهش قدرت جوندگى و جمع شدن صورت و زيبايى

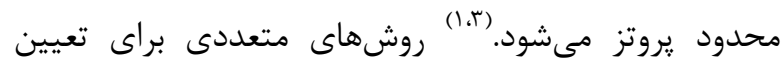

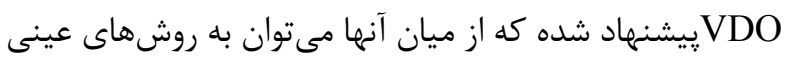

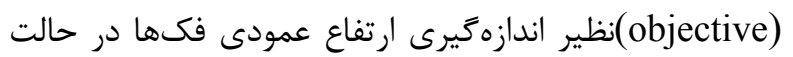
اكلوزن بر اساس نسبتهاى صورتى اشاره نمود. در يك صورت متقارن، ميان فاصلههاى كَوناگون نسبت طلايى وجود دارد.

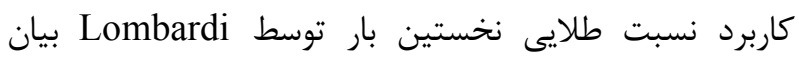

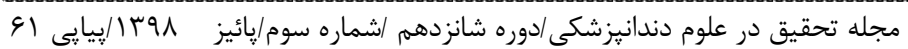




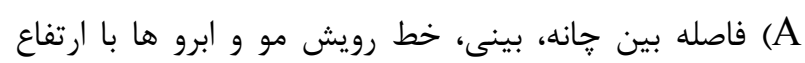

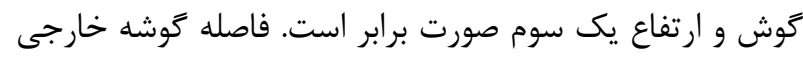
جشم تا گَوش با ارتفاع گوش و ارتفاع يك سوم صورت برت برابر B ارتفاع صورت (از خانه تا خط رويش مو) با ارتفاع دست

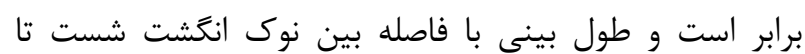

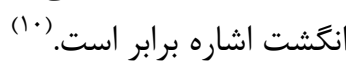

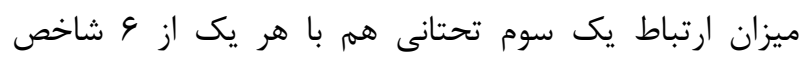

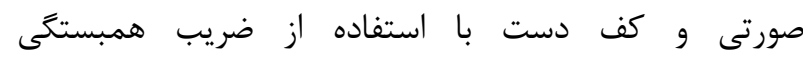
Pearson

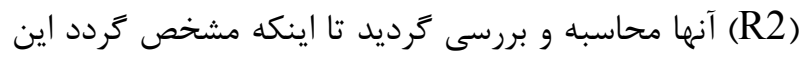

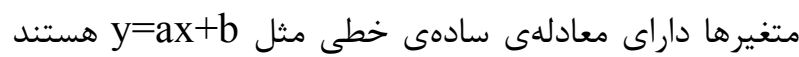

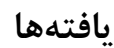

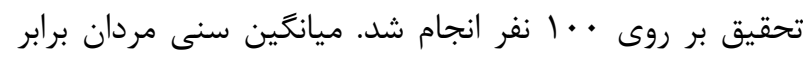

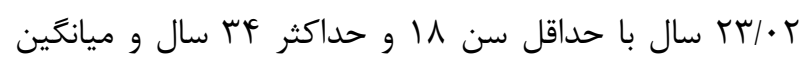

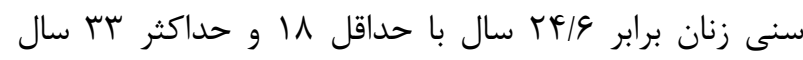

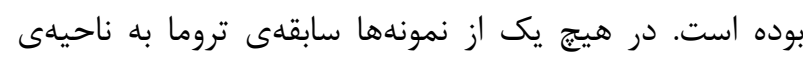

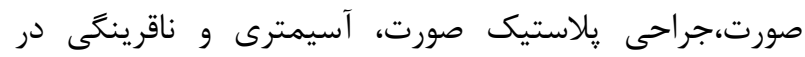
ناحيه صورت، استرابيسم و سابقهى درمانهاى ارتودنسى ثابت

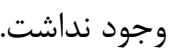
در جدول ا، ميزان همبستگى در ..1 نفر نشان داده شده

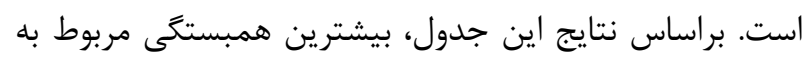

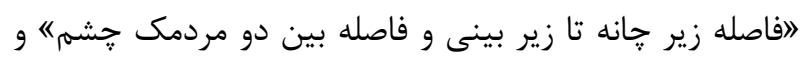

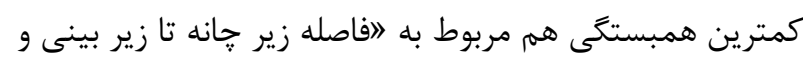
فاصله خط رويش مو و بين دو ابروه بود همبن همبن

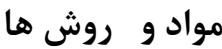

تحقيق به روش توصيفى و از نوع همبستكى روى ·.

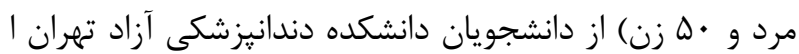

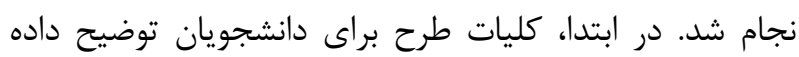

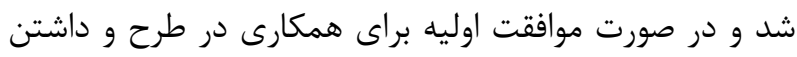

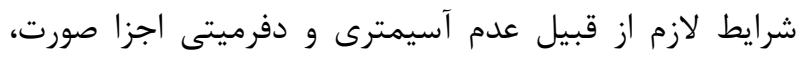

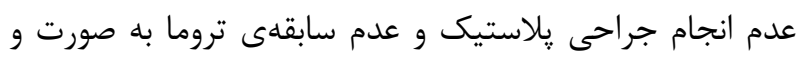
نيز عدم انجام درمانهاى ارتودنسى ثابت،دانشجويان وارد باري بررسى شدند. در صورت نداشتن شرايط مورد نياز، افراد از بر برى حذف ترديدند. نمونهها در حالت استراحت و در وضعيت قائم نشسته و به روبه برديه رو نحَاه مى كردند، در حاليكه دندانهاى آنها در اكلوزن قرار

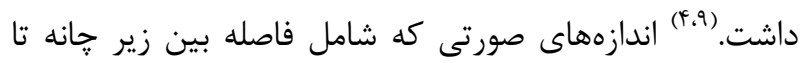
زير بينى، فاصله بين خط رويش مو و بين دو ابرو، فاصله بين

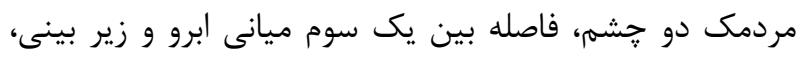
فاصله بين مردمك جشم و خط عرضى بين دو لب و نيز اندازه كف دست كه شامل فاصله بين مج تا بلندترين نقطهى انخشت

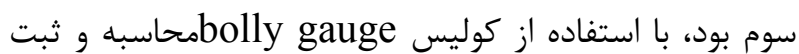

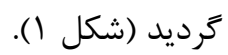

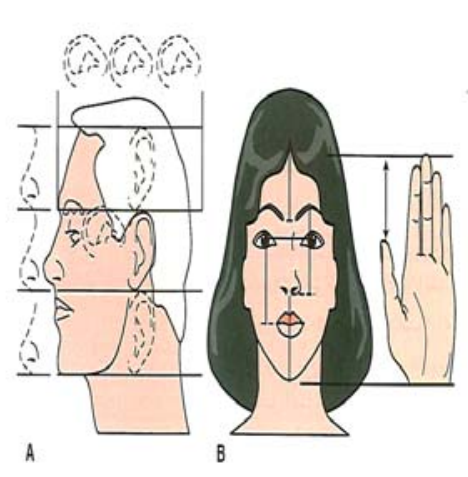

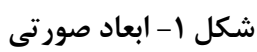

ابعاد صورتى با استفاده از يكى از روشهاى زير قابل محاسبه مىباشند: - معاد 
جدول r- ميزان همبستكى برحسب شاخصها به تفكيك جنس در دانشجويان دانشكده دندانيزشكى دانشكاه آزاد اسلامى واحد

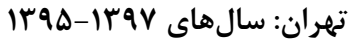

\begin{tabular}{|c|c|c|c|c|}
\hline برآورد همبستخى & $\begin{array}{c}\text { ميزان همخوانى } \\
\text { R }^{2}\end{array}$ & ميزان همبستخى & همبستخى & شاخص جنس \\
\hline كم & $.1 \cdot e^{c}$ & $\cdot / 4$. & مرد & \multirow{2}{*}{ خاصله زير خانه تا } \\
\hline كم & $\cdot 1 \cdot 1$ &.$/ 79$ & زن & \\
\hline عدم همبستخى & .1 .4 &.$/ 1 V$ & مرد & \multirow{2}{*}{ 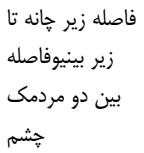 } \\
\hline خوب & . & $\cdot / 9 \Delta$ & زن & \\
\hline كم & .111 &.$/ \mu r$ & مرد & \multirow{2}{*}{ 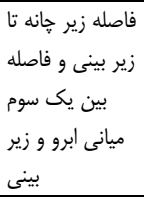 } \\
\hline كم & .1 .9 & $\cdot / T \Delta$ & زن & \\
\hline متوسط & $\cdot / r$. & $\cdot /{ }^{2} \Delta$ & مرد & \multirow{2}{*}{ 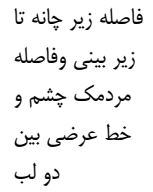 } \\
\hline عدم همبستَّى &.$/ \cdot 1$ &.$/$. & زن & \\
\hline عدم همبستكى & $.1 \cdot 1$ &.$/ 1 Y$ & مرد & \multirow{2}{*}{ فاصله زير خانه تا } \\
\hline عدم همبستخى & .1. & $.1 .+$ & زن & \\
\hline
\end{tabular}

طبق نتايج تحقيق حاضر، به طور كلى بين ارتفاع يك سوم تحتانى صورت با نسبتهاى صورتى همبستكى ديده نشد. البته بيشترين مقدار همبستكى مربوط به شاخص لايك سوم ميانى ابرو و زير بينى" و كمترين ميزان آن هم مربوط به شاخص "فاصله خط رويش مو و بين دو ابرو" بوده است. از طرف ديخر، همبستگى كليه شاخصهاى ينجكانه معادل أ|F/· برآورد

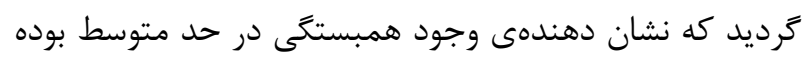
است. در بررسى شاخصها به تفكيك جنس هم، بيشترين

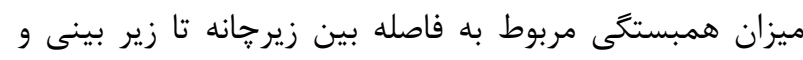
مردمك بين دو جشمدر زنان بود كه همبستكى خوبى داشته ولى در مردان، اين ميزان همبستكى قابل توجه نبوده است. doNascimento و همكاران در بررسى اثرات جنسيت، قد و وزن بر روى نسبتهاى صورتى در افراد برزيلى هم هيج
در جدول rا، ميزان همبستگى بين شاخصها به تفكيك جنس نشان داده شده است. براساس نتايج اين جدول و در زنان بيشترين مقادير همبستخى مربوط به لافاصله زير خانه تا زير بينى و فاصله بين دو مردمك جشمه و كمترين مربوط به "فاصله زير קانه تا زير بينى و اندازه كف دسته بوده است. در مردان هم، بيشترين همبستگى مربوط به الفاصله زير خانه تا زير بينى و فاصله مردمك خشم و خط عرضى بين دو لبه و كمترين مقادير همبستكى مربوط به اناصله زير خانه تا زير بينى و اندازه كف دست " بوده است.

جدول ا- ميزان همبستكى برحسب شاخصها در دانشجويان

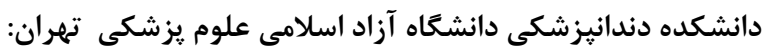

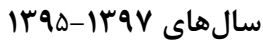

\begin{tabular}{|c|c|c|c|}
\hline همبستخى & $\begin{array}{l}\text { همخوانى } \\
\text { R } \\
\text { R }^{2}\end{array}$ & همبزان & همبستخى \\
\hline 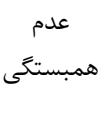 &.$/ \cdot T$ & $\cdot / 10$ & 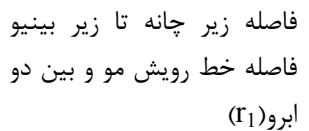 \\
\hline متوسط & . & $\cdot / 4 \wedge$ & فاصله زير خانه تا زير بينى \\
\hline متوسط & $\cdot / T V$ & - $/ \Delta T$ & 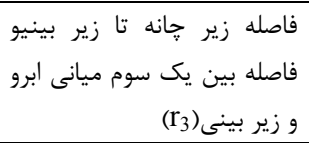 \\
\hline متوسط & $\cdot|\pi|$ &.$/ 48$ & فراصله زير خانه تا زير بينى \\
\hline متوسط & $\cdot|r|$ & $\cdot / 49$ & 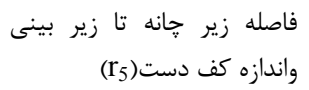 \\
\hline
\end{tabular}


اخير همبستگى متوسطى(r=/rV نشان داد كه اين نتايج با يافتههاى تحقيق حاضر كه در آن همبستخى خوبى بين دو متغير ديده شد، مغايرت دارد.در تحقيق اخير، اين شاخص همبستكى متوسطى با ارتفاع فوقانى صورت در مردان نشان داده و بقيهى شاخصها همبستخى ضعيفيداشته يا هيج همبستخى در آنها مشاهده نخرديد. (^)

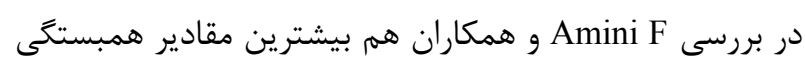
ناحيهى يك سوم تحتانى با فاصلهى گوشه خارجى جشم تا كوشهى خارجى دهان به ثبت رسيد كه برابر VY / • بوده

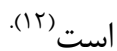

روشهاى متعددى براى تعيين VDOوجود داشته و برخى مطالعات هم دربارهى درستى و صحت اين روشها بررسى شدهاند. از جملهى اين روشها مىتوان به ثبت رابطهى عمودى free way در وضعيت استراحت فك يايين و كم كردن space رابطهى صحيح از زاويهى ANS-Xi-D ) ANS: خار قدامى لرون بينى، Xi: مركز راموس منديبل و D: مركز سمفيز منديبل) در سفالومترى بيماران، استفاده از روشهاى فونتيك و در نهايت،

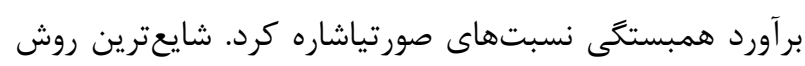
براى برآورد VDO همان ثبت رابطهى فيزيولوزيك در وضعيت استراحت بيمار است كه البته اين روش، دقيقترين روش نمىباشد (r). در بررسى Enklingو همكاران در دانشعاه Bonn آلمان، ميانگين زاويهى ANS-Xi-D در بيمارانى كه با استفاده از روش فيزيولوزيك ثبت رابطه شده بودند، برابر س/N

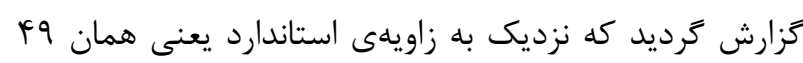

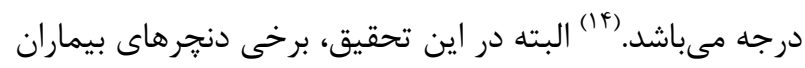
داراى VDO بلند و برخى از آنها داراى VDO كوتاه بودند كه اين امر نشان دهندهى اين موضوع است كه استفاده از

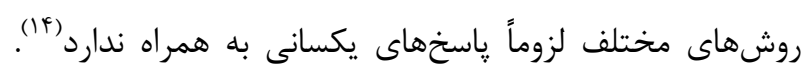
در تحقيق حاضر، تلاش گرديد كه اندازهها با استفاده از كوليس
همبستگى بين ارتفاع و اندازههاى آنترويومتريك صورت شناسايى نكردند كه از اين نظر، يافتههاى تحقيق اخير با نتايج تحقيق حاضر همخوانى دارد.(4) در تحقيق حاضر، نمونهها از جامعهاى با نزاد و فاصلهى جغرافيايى زياد نسبت به جامعهى برزيلى و از جامعهى ايران انتخاب شده و لذا، ارزيابى صحت

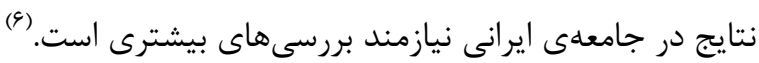
در مطالعهاى ديخر، Farkas و همكاران(مقادير ميانگين و همبستخى نسبتهاى خطى صورت در نزادسفيديوست آمريكايى را بررسى و نشان دادند ميانگين نسبت ارتفاع قانه به ارتفاع يك سوم تحتانى صورت در هر دو جنس در اين نزاد تقريباً يكسان بوده و همبستخى اين دو شاخص هم خوب بوده است(r r r r). در تحقيق اخير، همبستگى ارتفاع يك سوم تحتانى صورت با ارتفاع ورميليون لب پايين در مردان در محدودهى خوب (r=/VT) و در زنان متوسط (r=) (r=) برآورد شده ولى شاخص يك سوم تحتانى صورت با شاخص ديگرى مقايسه نخرديد (V). (V). Yamashita S ايرانى - منتخب از له زيرگروه نزادى -را بررسى و نشان دادند تمام اندازهها در مردان بزرگتر از زنان بوده است. (1) مقايسهى نتايج بررسى امينى و همكاران با نتايج Farkas و همكاران هم نشان دادند ارتفاع صورت و ارتفاع فوقانى صورت مردان ايرانى نسبت به نزاد آمريكايى بزرت تر بوده است (V.II) بررسى ديخرى هم توسط Majeed و همكاران در عربستان سعودى و با هدف تعيين همبستخى اندازهاى كرانيوفاسيال با

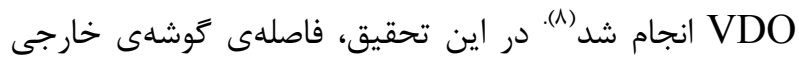
ابروى راست با گوشهى دهان در سمت راست، بيشترين همبستخى را با يك سوم تحتانى صورت در مردان( ( وزنان(צr=•(r =)داشته و نيز شاخص طول ورميليون لب بالا از يك گوشه تا گوشه ديخر دهان، همبستخى متوسطى در مردانبه

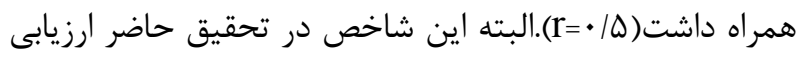
نكرديد. شاخص فاصلهى مردمك جشمها در زنان در تحقيق 
نقش آنها تعيين كننده و قطعى نبوده است. به نظر مىرسد

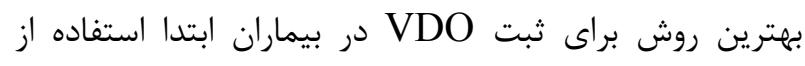

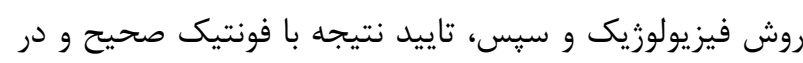
نهايت استفاده از نسبتهاى صورتى باشد. همزمان، از جمله

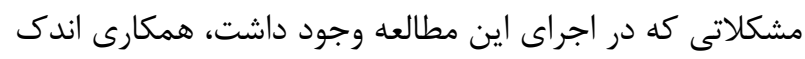
دانشجويان در نمونه

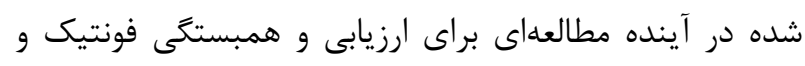
closest speeking space

نتيجه

در مجموع، شاخصهاى آنترويومتريك و دست در تعيين ارتفاع

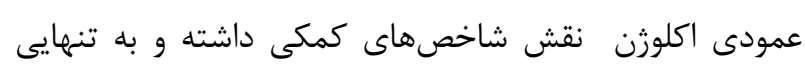

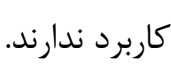

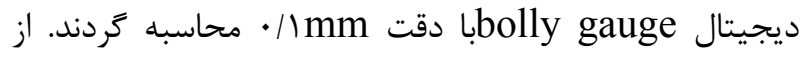
طرف ديخر، تعداد نمونههاى كافى در تحقيق بررسى گرديد. با بال

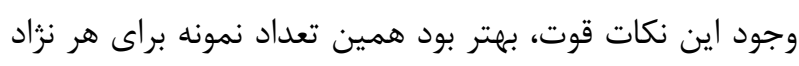

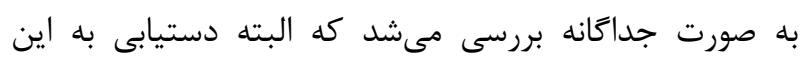

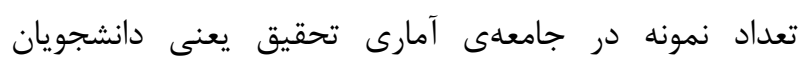

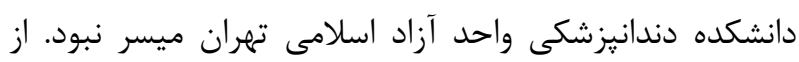
طرف ديكر، دربارهى موضوع سن نمونهها هم بهتر است تحقيق بر روى افراد بادندان داراى سنين بالاتر انجام شود.

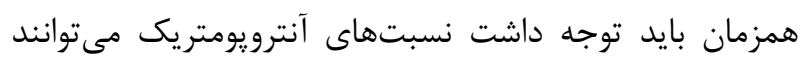
فقط نقش كمك كننده براى انتخاب VDO صحيح داشن داشته باشند، طورى كه اين نسبتها در تحقيق حاضر همبستكى نه

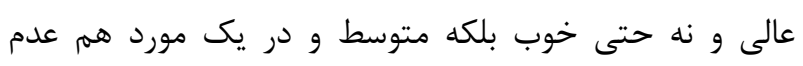
همبستخى با ارتفاع يك سوم تحتانى صورت داشته و در نتيجه، 


\section{References:}

1-khanehzad M,Madadi S.Tahmasebi F.Khazemzadeh S.Hassanzadeh G. The correlation between occlusal vertical dimention, length of the thumb and facial landmarks measurements: An Anthropometric study of Iranian university students. Global journal of human anatomy and physiology research 2018;4:1-6.

2-Yagi T,Morimoto T,Hidaka O,Iwata K,Masuda Y,Kobayashi $M$, et al .Adjustment of the occlusion vertical dimension in the bite-raised guinea pig. J Dent Res 2003;82(2):127-30.

3-Mohindra NK,Bulman JS. The effect of increasing vertical dimension of occlusion on facial aesthetics. Br Dent J 2002;192(3):164-8.

4-Lombardi RE. The principles of visual perception and their clinical application to denture esthetics. J Prosthet Dent 1973;29(4):358-82.

5-Levin EL. Dental esthetics and the golden proportion. J Prosthet Dent 1978;40(3):244-52.

6-doNascimento WV,de AguiarCassiani R, Dantas RO. Effect of gender, height and race on orofacial measurements.CoDAS 2013;25(2):149153.

7-Farkas LG,Katic MJ,Hreczko TA,Deutsch C,Munro IR. Anthropometric proportions in the upper lip-lower lip-chin area of the lower face in young white adults.Am J Orthod 1984;86(1);5260.

8-Majeed MI, Haralur SB, Khan MF, Al-Ahmari MA, Al-Shahri NF, Shaik SH. An anthropometric study of cranio-facial measurements and their correlation with vertical dimension of occlusion among Saudi Arabian subpopulations.J Med Sci 2018;6(4):680-6.

9-Alhajj MN, Daer AA. A proposed linear skeletal distance to predict occlusal vertical dimention:A cephalometric study. The journal of prosthetic dentistry 2017;118(6):732-5.

10-Bonakdarchian M, Tavangar A. Assesment of correlation of vertical dimension of jaws in occlusion with facial indices.The journal of dentistry shiraz university of medical sciences 2009;10(1):73-8.
11.Yamashita S,Shimizu M,Katada H. A newly proposed method to predict optimum occlusal vertical dimention. Journal of prosthodontics 2015;24(4):287-90.

12.Amini F, Mashayekhi M, Rahimi H, Morad G. Craniofacial morphologic parameters in a Persian population: an anthropometric study. J CraniofacSurg 2014;25(5):1874-81.

13. Aziz Miran F, Ahmed Mehmood Kh. The cottelation between the right lttle finger, eye-ear distance and vertical dimension of occlusion among students of faculty of medical sciences in university of sulaymani. IOSR JDMS 2015;14(12):69-73.

14.Enkling N, Enkling-Scholl D, Albrecht M, Bornstein M, Schimmel M. Determination of the occlusal vertical dimension in edentulous patients using lateral cephalograms. J Oral Rehabil 2018;45(5):399-405. 